\title{
The c-Jun $\mathrm{NH}_{2}$-terminal kinase3 (JNK3) gene: genomic structure, chromosomal assignment, and loss of expression in brain tumors
}

Received: December 12, 2000 / Accepted: January 5, 2001

\begin{abstract}
By examining 19 human cell lines derived from brain tumors for altered expression of expressed sequence tags (ESTs) in chromosomal band 4q21-22, we detected loss of expression, in 10 cell lines, of two sequences, WI6336 and WI7913. Both corresponded to the c-Jun $\mathrm{NH}_{2}$-terminal kinase (JNK) 3. In the present study, genomic cloning revealed that the $J N K 3$ gene consists of 14 exons interrupted by 13 introns; its transcription-initiation site is within exon 3 and the termination codon lies in exon 14. Fluorescence in situ hybridization (FISH) and radiation-hybrid mapping confirmed the gene to $4 \mathrm{q} 21-22$. Together with prior evidence that, in $J N K 3$-deficient mice, the JNK3 signaling pathway mediates apoptosis in central nervous tissue, our results suggest that loss of expression of the $J N K 3$ gene may play an important role in the development of brain tumors in humans.
\end{abstract}

Key words $J N K 3$ - Brain tumor • Genomic structure • Single-nucleotide polymorphism $\cdot 4 q 21-22$

\section{Introduction}

Allelic losses (loss of heterozygosity; LOH) in specific chromosomal bands that occur frequently in human cancers suggest that tumor suppressor genes are present within the affected regions. For example, human cancers frequently show LOH on the long arm of chromosome 4, e.g., breast carcinomas (Shivapurkar et al. 1999), osteosarcomas

S. Yoshida $\cdot$ K. Fukino $\cdot$ H. Harada $\cdot$ H. Nagai $\cdot$ M. Emi $(\square)$

Department of Molecular Biology, Institute of Gerontology, Nippon Medical School, 1-396 Kosugi-cho, Nakahara-ku, Kawasaki 211-8533, Japan

Tel. +81-44-733-5230; Fax +81-44-733-5192

e-mail: memi@nms.ac.jp

K. Fukino $\cdot$ H. Takahashi $\cdot$ A. Teramoto

Department of Neurosurgery, Nippon Medical School, Tokyo, Japan

I. Imoto $\cdot$ J. Inazawa

Medical Research Institute, Tokyo Medical and Dental University,

Tokyo, Japan
(Simons et al. 1999), esophageal adenocarcinomas (Rumpel et al. 1999), and oral squamous cell carcinomas (Wang et al. 1999); we ourselves have defined a 1-cM region at chromosome 4q21-22 that is commonly deleted in hepatocellular carcinomas (Bando et al. 1999).

The $J N K 3$ gene is a member of the c-Jun $\mathrm{NH}_{2}$-terminal kinase (JNK) group of mitogen-activated protein (MAP) kinases and is specifically expressed in the brain (Gupta et al. 1996). In $J N K 3$-deficient mice, the $J N K 3$ signaling pathway has been shown to mediate apoptosis in the central nervous system (Yang et al. 1997). Other members of the group, the $J N K 1$ and $J N K 2$ genes, were localized to chromosome 10 and chromosome 5q35, respectively. All isoforms from these genes have a conserved Thr-Pro-Tyr motif in protein kinase subdomain VIII, and differ in their interaction with substrates, that is, ATF2, Elk-1, and Jun transcription factors.

Because the downregulated expression of critical genes, in addition to the mutational inactivation of classical tumor suppressors, may be associated with tumorigenesis, we evaluated the expression of genes located in the 4q21-22 region, by carrying out reverse transcription-polymerase chain reaction (RT-PCR) experiments to amplify expressed sequences in tumor-cell lines. In the present study, we show that, among 12 expressed sequence tag (EST) markers in the 4q21-22 region, 2, which corresponded to the JNK3 gene, showed loss of expression in 10 of 19 cell lines derived from brain tumors; we also describe the genomic structure of the JNK3 gene and its chromosomal localization and single-nucleotide polymorphisms.

\section{Materials and methods}

Strategy for expression analysis using ESTs within the $4 q 21-22$

Expressed sequence tags (ESTs) from an interval flanked by D4S3011 and D4S2929 on 4q21-22 (human GeneMap 99 and Whitehead Institute Genome Database) were obtained 
from Genome Systems (St. Louis, MO, USA) and verified by sequencing. Each clone was examined for altered expression in brain-tumor cell lines by a semiquantitative RT-PCR method, using given primer sets.

Cell culture

A total of 19 brain-tumor cell lines were analyzed: A172, BT1, BT2, BT3, BT4, BT5, BT6, D283 Med, Daoy, DBTRG-05MG, GI-1, KG-1-C, SW1088, SW1783, TE6712, U251, U-118MG, U-138MG, and U-373MG. The cells were donated either by the Cell Resource Center for Biomedical Research at the Institute of Development, Aging and Cancer, Tohoku University; or by the Institute of Physical and Chemical Research (Riken) Cell Bank, Tsukuba, Japan (RCB); or purchased from the American Type Culture Collection (ATCC; Rockville, MD, USA). Each cell line was cultured under the optimized conditions recommended by its distributor.

DNA and RNA extraction and reverse transcription (RT)

DNA was extracted from 36 brain-tumor samples, obtained at surgery at Nippon Medical School Hospital, by phenolchloroform procedures described previously (Emi et al. 1999). Total RNA from 19 brain-tumor cell lines was extracted using a detergent reagent, following procedures described elsewhere (Kitamura et al. 1999). Each mRNA was prepared from $1 \times 10^{8}$ cells by the oligo-dT cellulose method (FastTrack 2.0 Kit; Invitrogen, Carlsbad, CA, USA), according to the manufacturer's instructions. Reverse-transcriptions were carried out using a SMART (Switching Mechanism At 5' end of RNA Transcript) RACE (rapid amplification of cDNA ends) cDNA amplification kit (Clontech, Palo Alto, CA, USA) following the manufacturer's instructions.

Polymerase chain reaction and RT-PCR

Each PCR was performed in a 30- $\mu$ l reaction volume, containing 10 pmol of each primer, $1 \times$ PCR buffer with $1.5 \mathrm{mM}$ $\mathrm{MgCl}_{2}$, and 0.5 units of Taq DNA polymerase, for 27 cycles, a condition that we empirically determined to enable comparison of gene-expression levels by means of ethidiumbromide staining after electrophoresis in agarose gels. Thermo-cycle conditions for amplification were described previously (Tsukamoto et al. 1998; Watanabe et al. 1998). To quantify the expression levels relative to other genes, we carried out duplex PCR experiments using primers to amplify Glucose-3-phosphate dehydrogenase (G3PDH) (forward, 5'-ACCACAGTCCATG CCATCAC-3'; reverse, $5^{\prime}$-TCCACCACCCTGTTGCTG TA-3') as an internal control (Fig. 1).

\section{Cloning a full-length cDNA}

To obtain the full-length cDNA sequence of $J N K 3$, the gene corresponding to two ESTs that showed downregulation, we carried out $5^{\prime}$ rapid amplification of cDNA ends ( $5^{\prime}$ RACE) experiments using the partial cDNA sequence of the JNK3 gene deposited in the GenBank database under accession no. HSU34820, and a SMART RACE cDNA amplification kit (Clontech). In brief, poly(A) RNA from a human heart (Clontech), was first reverse-transcribed with Superscript II reverse transcriptase (GIBCO-BRL, Gaithersburg, MD, USA), using an oligo(dT) primer. First-strand cDNA was subjected to two rounds of PCR as follows: the first reaction employed an outer adapter primer (AP1) and a gene-specific primer (5'CACTTCCACACTGTAGAACTGGTTGTCAACTTTG$\left.3^{\prime}\right)$ that corresponded to nucleotides $217-250$ of the archived partial cDNA. An aliquot of the first PCR reaction mixture was used as a template for nested PCR, using the nested adapter primer AP2 and a nested gene-specific primer (5'-GGCAATTTTCACATCCAATGTTGGTT CACTGCAG-3'), corresponding to nucleotides 115-148 of the partial cDNA. The PCR products were resolved by electrophoresis in a 1\% agarose gel; the specific PCR product visualized by ethidium-bromide staining was purified with a gel extraction kit (Qiagen, Tokyo, Japan) and subcloned using an AdvanTAge PCR cloning kit (Clontech). The nucleotide sequence of the cDNA was determined by the BigDye Terminator cycle sequencing method, using a 377 ABI Prism automated DNA sequencer (Perkin-Elmer, Norwalk, CT, USA).

\section{Isolation of the human $J N K 3$ gene}

A bacteriophage P1-derived artificial chromosome (PAC) library and a bacterial artificial chromosome (BAC) library containing human genomic DNA pooled in a threedimensional structure (Genome Systems, St. Louis, MO, USA; Research Genetics, Buffalo, NY, USA) were used to isolate genomic clones of JNK3. These libraries were screened by a PCR method described previously (Tsukamoto et al. 1998), using two oppositely oriented oligonucleotides (forward, 5'-TGACATCTCCTCCATG TCCA-3'; reverse, 5'-AGTAA GCATCATTGGAAGA AGACC-3') for screening the PAC library (exons 4-14). For screening the BAC library, we used three primer sets, consisting of (forward) 5' -ATCTCAGATCTTCACTATGG-3' and (reverse) 5'-TGTATGGTTTCTCATCTATA-3' (exon

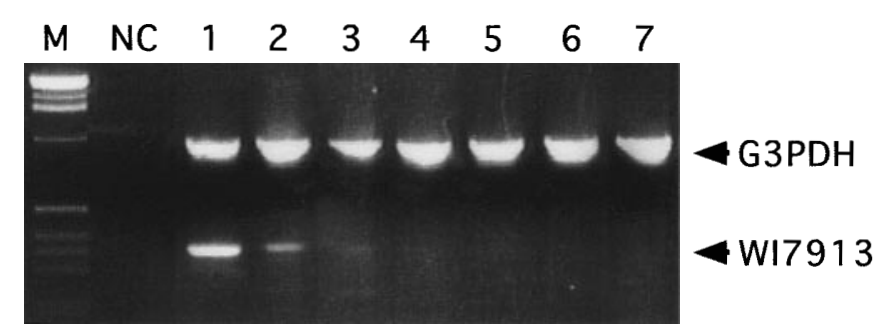

Fig. 1. Reverse transcription-polymerase chain reaction (RT-PCR) analysis of WI7913 (JNK3) expression in brain-tumor cell lines. Lane 1 contains cDNA from normal whole brain; lanes 2-7 contain cDNAs from the following cell lines: lane 2, D283 Med; lane 3, KG-1-C; lane 4, GI-1; lane 5, SW1783; lane 6, U251; lane 7, Daoy. M, Size marker; NC, negative control; G3PDH, glucose-3-phosphate dehydrogenase 
3); (forward) 5'-GAGCCCAGAGGGATTTTG-3' and (reverse) 5'-TCAATTTAGAGAGCTGCGTG-3' (exon 1); and (forward) 5'-GTATTTATGAGCCTCCATTTC-3' and (reverse) 5'-CTGACAAAAGGCAATTTTCAC-3' (exon 2). The BAC primers corresponded respectively, to EST (WI7913), to nucleotides 1-78 of the partial cDNA, and to the sequence we obtained by $5^{\prime}$ RACE. Escherichia coli cells containing positive clones were cultured in the presence of kanamycin or chloramphenicol, and PAC or BAC DNA inserts were isolated as described previously (Tsukamoto et al. 1998).

Sequence analysis of exon/intron junctions

Nucleotide sequences of exons and their boundaries were determined by direct sequencing of the PAC or BAC clones, or by long and accurate (LA)-PCR, using primers designed from the archived partial cDNA sequence of $J N K 3$. Primers for sequencing the exon/intron junctions of exons 1 and 2 were designed from the full-length JNK3 cDNA we obtained by $5^{\prime}$ RACE. Sequencing was performed by the BigDye Terminator cycle sequencing method, using a 377 ABI Prism automated DNA sequencer (Perkin Elmer). The size of each intron was estimated by PCR amplification, using LA Taq (Takara, Tokyo, Japan) with two oppositely oriented primers located in the exons flanking each intron.

Fluorescence in situ hybridization (FISH)

A PAC clone carrying the human gene was used as a probe for FISH analysis, which was carried out as described by Mukae et al. (1998). The PAC DNA was labeled with biotin-16-2'-deoxy-uridine-5'-triphosphate (biotin-16dUTP) by nick-translation and hybridized to denatured chromosomes, at a final concentration of $25 \mathrm{ng} / \mathrm{ml}$ in $50 \%$ formamide, $10 \%$ dextran sulfate, $2 \times$ standard saline citrate (SSC), $0.2 \mathrm{mg} / \mathrm{ml}$ Cot-1 DNA (GIBCO/BRL), $2 \mathrm{mg} / \mathrm{ml}$ salmon sperm DNA, and $2 \mathrm{mg} / \mathrm{ml}$ E. coli tRNA. The hybridized signals were detected with fluorescein isothiocyanateavidin (Boehringer Mannheim, Mannheim, Germany).
Cells were counterstained with 4',6-diamidino-2phenylindole, and the slides were examined through a Nikon epifluorescence microscope (Nikon, Tokyo, Japan), equipped with a charge-coupled device (CCD) camera (Photometrics, Tucson, AZ, USA). Images were captured with Quips (Vysis, Tokyo, Japan) software and processed with Adobe Photoshop 3.0 software (Adobe systems, San Jose, CA, USA).

Radiation-hybrid mapping

The G3 RH mapping panel from the Stanford Human Genome Center (Boehnke et al. 1991), was used to confirm and define further the chromosomal location of the JNK3 gene. Typing was carried out using opposing primers located in the introns flanking exon 1 (forward: 5'TCTGTTGAGTCTGCACACTG-3'; reverse: 5'-AGGA ATACATTAGGAATGCCG-3'), exon 2 (forward: 5'TCAAACTCATCTGTTTTTTGGC-3'; reverse: 5'AGATCCTAGTTTTCATGCTAAG- $3^{\prime}$ ), exon 3 (forward: 5'-GTATAGTACAGGTCAAGATAAGG-3'; reverse: 5'-GGAATGTATGCAAATGGTATGTC-3'), and exon 5 (forward: $5^{\prime}$-TGAGTTGCTCTTGGATCTC$3^{\prime}$; reverse: $5^{\prime}$-ATCTTACAAACTCCACTGC-3'). The results of maximum-likelihood analysis were obtained by submitting the raw scores to http://www-shgc.stanford.edu.

Single-strand conformational polymorphism (SSCP) analysis with silver staining

To look for possible alterations in the JNK3 gene, we amplified each exon and its flanking regions with appropriate primers (Table 1), in genomic DNAs from 36 primary brain tumors. About $10 \mathrm{ng}$ of each PCR product was heatdenatured in the presence of deionized $80 \%$ formamide and electrophoresed in $8 \%$ polyacrylamide gels, with or without $10 \%$ glycerol, in $0.5 \times$ tris-borate/EDTA $(\mathrm{TBE})$, at $8 \mathrm{~V} / \mathrm{cm}$ for $10 \mathrm{~h}$ at room temperature (Hirayama et al. 1998). DNA fragments were visualized by silver staining, using the Plus One DNA silver-staining kit (Pharmacia Biotech, Tokyo, Japan). Each fragment showing an altered SSCP band pat-

Table 1. Primer sequences used for PCR-SSCP analysis

\begin{tabular}{clll}
\hline Exon & Forward primer $\left(5^{\prime}-3^{\prime}\right)$ & Reverse primer $\left(5^{\prime}-3^{\prime}\right)$ & Product size $(\mathrm{bp})$ \\
\hline 3 & TTGGAGATATGTTGTGCATGG & GGAATGTATGCAAATGGTATGTC & 266 \\
4 & CTTGCCTCATGTTTTTGCTG & TTCCCTTTAAAAATACAGCAAATCC & 242 \\
5 & TGAGTTGCTCTTGGATCTC & ATCTTACAAACTCCACTGC & 201 \\
6 & TCTTTCTCTCGTTTCTCTG & CCCTTCCTTCATGAGTTTG & 127 \\
7 & ACTAACACTGTGGATTCACC & AATTGTAATCCTAGAGAAGGTG & 195 \\
8 & TTAATTTTTCCCTTATCCTTACTG & TTTGATGCTGCTCTCCGAA & 223 \\
9 & CTCCTTCAGAAGTCAATTATC & TGCTTCTATCTTTACTCTCCTGG & 242 \\
$10-\mathrm{a}$ & TTGAAAGGCTAGTGGTCTGC & CCGATTCTCCACATAGTTC & 154 \\
$10-\mathrm{b}$ & GAAGAAATTGCAACCCACAG & CCCTCATAGTTGTCCTCAAG & 164 \\
11 & GAAATCAAAATCTTACTAATTGTTTTCTC & AAGCAAAGTAAAGGCAGCCT & 198 \\
12 & GTATTCTCGTGCATTGTAAGAG & GCCTTGTTGATACTTTCTGAG & 204 \\
13 & AATTTCCCTGTGGATGAAGG & CTAGTTTATTGGTTATTCACGG & 171 \\
14 & ATGGGTCTGGTTCTAGATTG & ATTGACAGACGAGGATGGAG & 101
\end{tabular}

PCR-SSCP, Polymerase chain reaction-single-strand conformation polymorphism 
tern was subcloned with an AdvanTAge PCR cloning kit (Clontech) and sequenced.

\section{Results and discussion}

Among ESTs from an interval flanked by D4S3011 and D4S2929 at 4q21-22, two (WI6336 and WI7913) showed loss of expression in 10 of the 19 brain-tumor cell lines examined. These two ESTs were found to be parts of the JNK3 gene, as they corresponded to the archived partial cDNA sequence (Genbank no. HSU34820). Because $J N K 3$ is selectively expressed in the brain, and a study of $J N K 3$-deficient mice had indicated that the $J N K 3$ signaling pathway mediates apoptosis in the nervous system, we considered that loss of expression of this gene might be associated with tumorigenesis in the human brain. To search for alterations in the $J N K 3$ gene, we characterized it at the genomic level and carried out PCR-SSCP experiments in brain tumors.
Genomic structure of the $J N K 3$ gene

We invoked the 5' RACE technique to identify an additional 200-bp sequence on the $5^{\prime}$ end of the partial JNK3 cDNA, and subjected the result to a basic local alignment search tool (BLAST) search; 132 bp of this sequence exactly matched the human MAP kinase mRNA archived as HSU07620 in the GenBank database.

The genomic region containing the human $J N K 3$ gene was cloned in a PAC (98k4) and three BACs $(269 \mathrm{j} 1,81 \mathrm{k} 15$, $171 \mathrm{~m} 15)$. The entire gene was found to consist of 14 exons interrupted by 13 introns (Fig. 2). The boundary sequences are shown in Table 2. Exon 6 was the smallest, at 59bp; other exons ranged in size from 64 to $434 \mathrm{bp}$. Sequences at the exon-intron boundaries for all 13 introns were compatible with the consensus sequence for splicing junctions, including GT-AG (Mount 1982).

Comparison of genomic and cDNA sequences revealed that exons 1 and 2 , and the $5^{\prime}$ half of exon 3 , encode the $5^{\prime}$ untranslated region (UTR), while the $3^{\prime}$ portion of exon 3

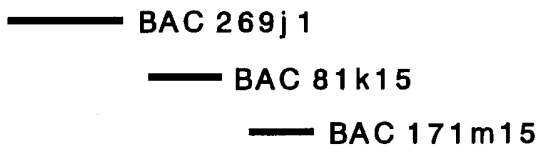

PAC $98 k 4$

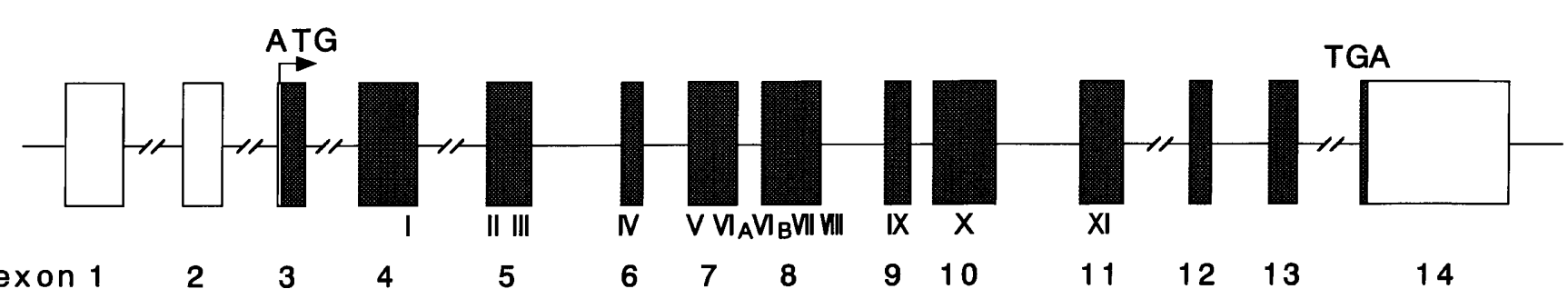

Fig. 2. Schematic structure of the human $J N K 3$ gene. Coding regions are indicated by filled boxes. Bacteriophage P1-derived artificial chromosome $(P A C)$ and bacterial artificial chromosome $(B A C)$ genomic

clones that cover the region are shown above the map. Conserved protein-kinase subdomains (Hanks et al. 1988) are indicated by Roman numerals

Table 2. Exon-intron boundary sequences of the $J N K 3$ gene

\begin{tabular}{|c|c|c|c|c|c|}
\hline $\begin{array}{l}\text { Exon } \\
\text { number }\end{array}$ & $\begin{array}{l}\text { Exon length } \\
\text { (bp) }\end{array}$ & $\begin{array}{l}\text { cDNA (HSU34820) } \\
\text { position }\end{array}$ & Splice acceptor & Splice donor & Intron size (kbp) \\
\hline 1 & 170 & & & TCAGCTCCAGgtaaggtcag & ND \\
\hline 2 & 115 & -85 & ttgctttcagGCTAGTGTGA & ACAAGCTGTGgtgagttgcc & ND \\
\hline 3 & 72 & $86-157$ & tttcctctagGTATTTATGA & CTTTTGTCAGgtgtgtgttc & ND \\
\hline 4 & 170 & $158-327$ & tttttgacagGGATTCGATA & GCATAGTTTGgtaagcggaa & ND \\
\hline 5 & 130 & $328-457$ & tgtgatacagTGCCGCGTAT & CCATAAAAACgtgagttttg & 3 \\
\hline 6 & 59 & $458-516$ & tctctttcagATTATTAGTT & TCCAAGATGTgtaagtaaca & 1.3 \\
\hline 7 & 139 & $517-655$ & accettctagTTACTTAGTA & TATTCACAGGgtaagaacac & 0.7 \\
\hline 8 & 166 & $656-821$ & ttactgttagGATTTAAAAC & AAGGAGAACGgtagggatgc & 2 \\
\hline 9 & 72 & $822-893$ & cctgttctagTGGATATATG & GGAAGGGACTgtatcettgt & 0.5 \\
\hline 10 & 183 & 894-1076 & caattctcagATATTGACCA & AAACTCAAAGgtatgccett & 3 \\
\hline 11 & 125 & 1077-1201 & attgtttcagCCAGCCAAGC & AGTGGAGGCGgtaagaaata & ND \\
\hline 12 & 64 & $1202-1265$ & tatttggcagССТССАССТС & GAATGGAAAGgtaagtctac & 1.8 \\
\hline 13 & 78 & $1266-1343$ & tttcttacagAACTTATCTA & ТСТССТТСAGgtactcactct & ND \\
\hline 14 & 434 & $1344-$ & attttcttagCACAGGTGCA & ATACCAATTTgtagaaagaa & \\
\hline
\end{tabular}

The lowercase letters refer to intron sequences, and the uppercase letters to exon sequences. The intron sizes were estimated as described in "Materials and methods". Bold face letters indicate consensus sequence for GT-AG rule

ND, Not determined 
Fig. 3. Nucleotide sequence of the newly characterized 5 'region of the JNK3 gene. The putative transcriptional-start site predicted by $5^{\prime}$ rapid amplification of cDNA ends (RACE) experiments is indicated by an asterisk

\author{
$-355$ \\ aggtcaatag agttatgttc ctaggaggat tatgtctgcc tttgctgtgt \\ -305 catgcagctt gccagggaag tgcgggcaag ctggcagtca caggcctcac \\ -255 ccagttccca cacaacgcaa acagctggtc tcactcccat tgtgccccca \\ -205 gcagcagcac caaggctgtc tccaggcagt gggcaagcag gaccgagtac \\ -155 tttccccagg ctacccgcct cccagctgtg aaataaaca gggctctcct \\ -105 tcttccetgc tctgttgagt ctgcacactg gattcatgcc ctccccetga \\ -55 gttctggcca agagacttct ccatcagttg aaattgttac aagttcagc \\ $-5$ \\ CTTCTCCCTG
}

through the $5^{\prime}$ portion of exon 14 encodes the translated region; the remainder of exon 14 encodes the 3'UTR (Fig. 2). The locations of conserved protein-kinase subdomains I-XI (Hanks et al. 1988) are also indicated in Fig. 2. Figure 3 shows the nucleotide sequence of the putative 5 '-flanking region of the $J N K 3$ gene; no CAAT or TATA box was present in the $5^{\prime}$-flanking region of the $J N K 3$ gene. These features are characteristic of the promoters of housekeeping genes (Dynan 1986).

\section{Chromosomal localization}

When a PAC genomic clone was used as a probe to confirm the localization of the JNK3 gene by FISH, clear signals were present on chromosomal band 4q21-22 (Fig. 4). The gene was also mapped to chromosome 4q21-22 by means of the G3 RH mapping panel of 83 hybrid cell lines from the Stanford Human Genome Center (Boehnke et al. 1991), through linkage to marker SHGC4-508, with a logarithm of the odds (LOD) score of more than 12.33.

Sequence variations in the $J N K 3$ gene

We amplified the entire coding region in each of 36 primary brain-tumor samples and screened the PCR products by SSCP analysis, followed by visualization with silver staining. PCR products with potential variations were sequenced directly by automated instruments. By comparing normal samples, we observed two polymorphisms within the $J N K 3$ gene, the first within exon 10 and the other in intron 5. These polymorphisms and their allelic frequencies are summarized in Table 3. As both variants were observed in normal samples, neither represented a somatic mutation that would account for the loss of expression we observed in tumor cells.

$J N K 3$ gene in brain tumorigenesis

JNK is a member of the MAP group of protein kinases, and it is found in at least ten isoforms that result from the

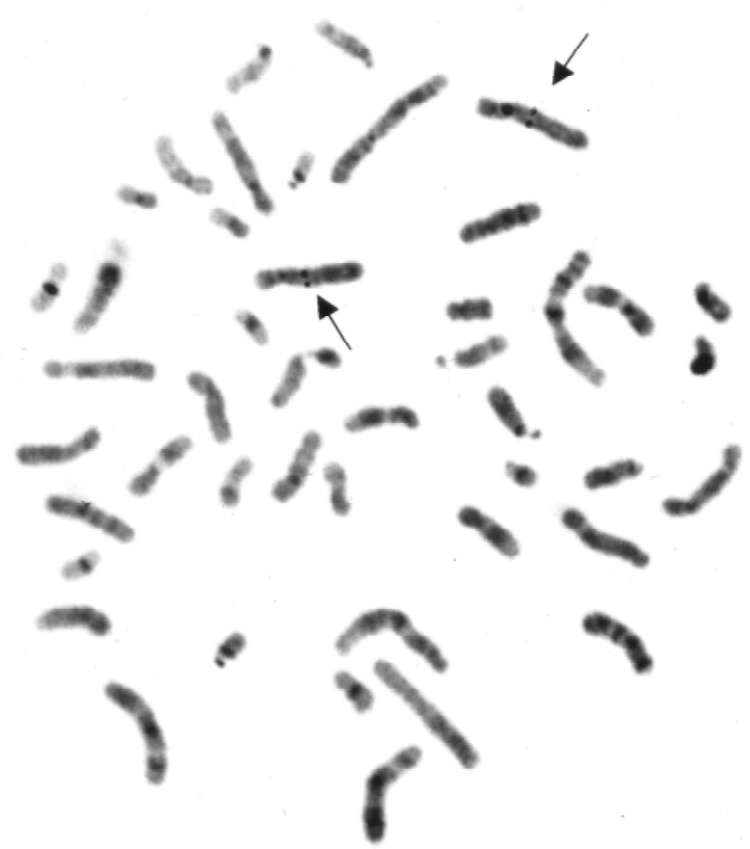

Fig. 4. Chromosomal localization of the human JNK3 gene to 4q21-22 (arrows) by fluorescence in situ hybridization

alternative splicing of three genes $(J N K 1, J N K 2$, and $J N K 3$; Gupta et al. 1996). JNK3 is selectively expressed in the brain and, to a lesser extent, in the heart and testis (Gupta et al. 1996). In $J N K 3$-deficient mice, the $J N K 3$ signaling pathway mediates apoptosis in the nervous system (Yang et al. 1997).

The study reported here revealed loss of expression of the $J N K 3$ gene in 10 of the 19 human brain-tumor cell lines we examined. Fresh primary cultures of brain tumors were not tested in the present study, because of unavailability. Future examination of gene expression, using such specimens, will be necessary to confirm role of the $J N K 3$ gene in brain tumorigenesis. Genes that frequently show decreased 
Table 3. Single-nucleotide polymorphisms found in the $J N K 3$ gene

\begin{tabular}{|c|c|c|c|c|c|c|c|c|}
\hline \multirow[b]{2}{*}{ Exon 10} & \multirow{2}{*}{$\begin{array}{l}\begin{array}{l}\text { Nucleotide } \\
\text { sequence }\end{array} \\
\text { GCG } \rightarrow \text { GCA } \\
\text { (Ala) (Ala) }\end{array}$} & \multirow{2}{*}{$\begin{array}{l}\begin{array}{l}\text { Codon } \\
\text { position }\end{array} \\
320\end{array}$} & \multirow[t]{2}{*}{$\begin{array}{l}\text { Nucleotide } \\
\text { position }\end{array}$} & \multicolumn{3}{|c|}{$\begin{array}{l}\text { Genotypes } \\
(n=34 \text { or } 35)\end{array}$} & \multicolumn{2}{|c|}{$\begin{array}{l}\text { Allelic } \\
\text { frequencies }\end{array}$} \\
\hline & & & & $\begin{array}{l}\mathrm{G} / \mathrm{G} \\
29\end{array}$ & $\begin{array}{l}\mathrm{G} / \mathrm{A} \\
5\end{array}$ & $\begin{array}{l}\mathrm{A} / \mathrm{A} \\
0\end{array}$ & $\begin{array}{l}\mathrm{G} \\
0.93\end{array}$ & $\begin{array}{l}\text { A } \\
0.07\end{array}$ \\
\hline Intron 5 & $\mathbf{A} \rightarrow \mathbf{G}$ & & -12 & $\begin{array}{l}\mathrm{A} / \mathrm{A} \\
10\end{array}$ & $\begin{array}{l}\mathrm{A} / \mathrm{G} \\
18\end{array}$ & $\begin{array}{l}\mathrm{G} / \mathrm{G} \\
7\end{array}$ & $\begin{array}{l}\text { A } \\
0.54\end{array}$ & $\begin{array}{l}\mathrm{G} \\
0.46\end{array}$ \\
\hline
\end{tabular}

Nucleotide position is identified from the exon-intron boundary. Bold face letters indicate singlenucleotide polymorphism (SNP)

expression in tumors are characterized as class II tumor suppressors (Zou et al. 1994). Our results suggest that the $J N K 3$ gene may belong to class II, because (1) it is located at $4 \mathrm{q} 21-22$, where $\mathrm{LOH}$ is common in tumors; (2) its expression has been lost in multiple lines of brain-tumor cells, and (3) it has not undergone detectable mutations in braintumor samples. Although no class I tumor suppressor has yet been identified from the $4 \mathrm{q} 21-22$ region, it is attractive to speculate that the regional inactivation of multiple genes from this chromosomal band contributes to tumor formation (Zou et al. 1994). However, because our analysis showed that $J N K 3$ is not a mutational target in brain-tumor cells, it is apparently inactivated by other mechanisms (e.g., allelic loss, methylation, or even haplo-insufficiency). Future studies should include functional analysis of this gene through transfection to cancer cells, or methylation analysis, once the promoter region is identified, to help clarify these issues.

Acknowledgments We thank Ms. Tomoko Atake and Ms. Tomoko Koguchi for their technical assistance. This work was supported in part by a Grant-in-Aid for Scientific Research Priority Area (C) on "Cancer" and "Genome Science" from the Ministry of Education, Science, Sports, and Culture of Japan; by a Research Grant from the Ministry of Health and Welfare of Japan; and by a Research for the Future Program Grant of The Japan Society for the Promotion of Science.

\section{References}

Bando K, Nagai H, Matsumoto S, Koyama M, Kawamura N, Onda M, Emi M (1999) Identification of a 1-cM region of common deletion on 4q35 associated with progression of hepatocellular carcinoma. Genes Chromosom Cancer 25:284-289

Boehnke M, Lange K, Cox DR (1991) Statistical methods for multipoint radiation hybrid mapping. Am J Hum Genet 49:11741188

Dynan WS (1986) Promoters for house-keeping genes. Trends Genet 2:196-197

Emi M, Keicho N, Tokunaga K, Katsumata H, Souma S, Nakata K, Taguchi K, Ohishi N, Azuma A, Kudoh S (1999) Association of diffuse panbronchiolitis with microsatellite polymorphism at the human interleukin 8 (IL-8) locus. J Hum Genet 44:169-172

Gupta S, Barret T, Whitmarsh AJ, Cavanagh J, Sluss HK, Derijard B, Davis RJ (1996) Selective interaction of JNK protein kinase isoforms with transcription factors. EMBO J 15:2760-2770

Hanks SK, Quinn AM, Hunter T (1988) The protein kinase family: conserved features and deduced phylogeny of the catalytic domains. Science 241:42-52

Hirayama T, Yamaki E, Hara A, Tsuji M, Hashimoto K, Yamamoto M, Emi M (1998) Five familial hypercholesterolemic kindreds in Japan with novel mutation of the LDL receptor gene. J Hum Genet 43:250-254

Kitamura Y, Nakata T, Minobe K, Shimizu K, Tanaka S, Fujimori M, Yokoyama Y, Ito K, Onda M, Emi M (1999) Ret/PTC3 is the most frequent form of gene rearrangement in papillary thyroid carcinomas in Japan. J Hum Genet 44:96-102

Mount SM (1982) A catalogue of splice junction sequences. Nucleic Acids Res 10:459-472

Mukae N, Enari M, Sakahira H, Fukuda Y, Inazawa J, Toh H, Nagata S (1998) Molecular cloning and characterization of human caspaseactivated DNase. Proc Natl Acad Sci USA 95:9123-9128

Rumpel CA, Powell SM, Moskaluk CA (1999) Mapping of genetic deletions on the long arm of chromosome 4 in human esophageal adenocarcinomas. Am J Pathol 154:1329-1334

Shivapurkar N, Sood S, Wistuba II, Virmani AK, Maitra A, Milchgrub S, Minna JD, Gazdar AF (1999) Multiple regions of chromosome 4 demonstrating allelic losses in breast carcinomas. Cancer Res 59:3576-3580

Simons A, Schepens M, Forus A, Godager L, van Asseldonk M, Mykelbost O, van Kessel AG (1999) A novel chromosomal region of allelic loss, 4q32-q34, in human osteosarcomas revealed by representational difference analysis. Genes Chromosom Cancer 26:115-124

Tsukamoto K, Ohta N, Shirai Y, Emi M (1998) A highly polymorphic CA repeat marker at the human interleukin 6 receptor (IL6R) locus. J Hum Genet 43:289-290

Wang XL, Uzawa K, Imai FL, Tanzawa H (1999) Localization of a novel tumor suppressor gene associated with human oral cancer on chromosome 4q25. Oncogene 18:823-825

Watanabe I, Tsukamoto K, Shiba T, Emi M (1998) Isolation and radiation hybrid mapping of dinucleotide repeat polymorphism at the human matrix Gla protein (MGP) locus. J Hum Genet 43:75-76

Yang DD, Kuan CY, Whitmarsh AJ, Rincon M, Zheng TS, Davis RJ, Rakic P, Flavell RA (1997) Absence of excitotoxicity-induced apoptosis in the hippocampus of mice laking the $J n k 3$ gene. Nature 389:865-870

Zou Z, Anisowicz A, Hendrix MJ, Thor A, Neveu M, Sheng S, Rafidi K, Seftor E, Sager R (1994) Maspin, a serpin with tumor-suppressing activity in human mammary epithelial cells. Science 263:526-529 